\title{
educação

\section{Inequalities and (in)justices in education: A dialogue with Sally Power}

\author{
Almerindo J. Afonso \\ ARMANDO LOUREIRO \\ JOANA LÚCIO
}

Within the framework of the EDUPLACES Project ${ }^{1}$, the arrival in June 2018 of the eminent teacher and researcher in education Sally Power from Cardiff University was an important opportunity, not only to benefit collectively from her presence as project consultant, but also, in a closer interaction, clarify some of her perspectives on the critical analysis on education and public policies.

Sally Power works at WISERD (Wales Institute of Social and Economic Research Data and Method), where she directs WISERD Education, a research and training programme for Wales. Her main area of expertise is the relationship between education, civil society and inequality, as well as the relative success and failure of educational policies aimed at promoting greater equality of opportunity. She is particularly wellknown for her work on introducing market reforms in England and in other countries, and on the relationship between education and the middle class. She investigates and publishes regularly on education policy, social mobility and intergenerational transmission; education in Wales; private education; longitudinal investigation. Her most recent publications also include research on the phenomenon of private tutoring and the relationship of third sector institutions with schools, higher education and the formation of elites.

Her research activities include assessments for various policy makers (the Welsh Government, the Scottish Executive, the UK Government), voluntary sector associations (Shelter, Field Studies Council) and the UK Research Council (ERSC). Between 2011 and 2014, she directed the Network of Experts on Social Aspects of Education and Training (NESET/Network of Experts on Social Aspects of Education and Training), funded by the European Commission. Until this year, she was the editor of the British Educational Research Journal.

\footnotetext{
${ }^{1}$ EduPlaces: Practices, Voices and Pathways of Inclusive Education (2016-2019) (PTDC/MHC-CED/3775/2014), financed by the Foundation for Science and Technology (FCT).
} 
Almerindo J. Afonso (AJA): Professor Sally Power, you have an extensive experience as a professor and researcher, and the objects of your research have been almost always concerned with the issues of inequalities and difference. Can you tell us what are the most important consequences of the fact, noticed in your work, that there is a "naturalisation of inequality"?

Sally Power (SP): First of all, thank you very much for your questions. Also, before I answer, can I just say how pleased I am to be here in the University of Minho, and how impressed I have been with some of the research that is going on. The issue of the "naturalisation of inequality" is something we have identified in relation to recent developments within the education community, to try and recognise inequality. We have always had inequalities and people have always, to some extent, argued that inequality is natural. But something has changed recently, and I think it has emerged out of various attempts to quantify the outcomes of education, to compare schools, to set targets, within an audit culture. So, if we look, for instance, particularly at England, in the 1980s we saw the emergence of league tables, which compared schools. So you would have a list with the most successful schools, that got the best results, at the top, and those at the bottom were those nearly always in the poorest areas. So, the schools at the top served advantaged students, and the schools at the bottom served disadvantaged communities. And, quite rightly, the education community said, "This is not fair; how can you compare the privileged with the disadvantaged?". What we need to do is find another way of gauging performance and success in schools. So, a lot of the education community, and particularly education researchers from the left, wanted to valorise the achievements of teachers working in very disadvantaged schools. So they have argued, successfully, to gauge performance, not on outcomes, but on improvements, so that, particularly in England, we have many league tables which are not about the best schools in terms of outcomes, but in terms of the schools which have improved the most. The schools which have improved the most often are those serving poor communities. And while, in one sense, that is admirable, because we are recognising that teachers and schools serving disadvantaged populations have a very hard job on their hands. On the other hand, it creates a sense that they are doing very well, even though their children are not succeeding. For instance, now, every school has a target, and that target depends on what levels of difficulty your school is dealing with, and the target for a school with a lot of difficulties is much lower. So, in this way, we normalise inequality, and instead of measuring success in terms of actual credentials, we measure success in terms of whether we have met what was expected of us. So, any measure that talks about 'valued added' or about 'improvement' basically naturalises inequality. It says, "This is the best you can expect to do with this child".

Joana Lúcio (JL): Could you explain a bit more what sort of improvements we are talking about? 
SP: If we take the standard measure of success, which is, when you are sixteen, whether you have got a certain level of qualification, that is the crude aspect of success. But there are other tests, where you can measure how much improvement you have made from fourteen to sixteen. So, you may still have failed the test, but you did better than you did at fourteen. Because we track students very often, we can see if they are making progress. So even if they have made progress, but still not reached the threshold that for most people counts as a 'success', this is classed as an improvement. What happens when you have 'value added' performance tables is you hide the inequalities that count. So, it worries me that you say to schools that they are doing a very good job, they are doing a good job, but the outcome is still very unequal.

JL: These children end up still being in disadvantage.

SP: Yes, because a 'value added' result does not get you into University. You do not go to University because you have improved; you go to University because you made the required threshold.

AJA: How do you think these issues equate with what Michael Young calls "powerful knowledge", for disadvantaged classes? The criticism that children from disadvantaged classes do not have access to "powerful knowledge", is it pertinent?

SP: There is a relationship. What you are trying to explain is why we have the inequalities, which is a different issue, which is about cultural deprivation theories, and how you can democratise access to powerful knowledge without devaluing other knowledges. So, it is a different kind of issue, but I think it is related.

JL: You mentioned the achievements of teachers, is that related to the 'added value' that you mentioned as well?

SP: Because value-added comparisons and other contextualised league tables (that adjust according to will say how many students have free school meals, how many have English as a foreign language, how many have special educational needs) grade schools according to their improvement, rather than their overall results, you valorise what teachers do.

JL: But is that the same for every school in the league tables? Do they all offer that contextual information?

SP: A lot of them do, yes, and that is partly because people on the left have argued for it, quite rightly, but it has an unintended consequence, that is my point.

AJA: What is your main criticism to this policy of differential assessment of outcomes? 
SP: That it hides the inequalities that matter. Because what you are doing is marginalising the inequalities. You are saying that, actually, the ultimate outcomes are less important than the progress you have made. And I think, for the young persons' lives, the ultimate outcomes are the most important thing, and the job of the research community is not to make teachers feel better about the fact that there are inequalities, it is to make them want to get rid of them, not to live with them.

AJA: So this policy is a form of legitimation of inequalities?

SP: Yes.

Armando Loureiro (AL): You argue that economic, cultural and political injustices lead to different kinds of exclusion. My question is, in what ways do these different forms of injustice materialise in the field of schooling? In what way do these injustices produce exclusions in schooling?

SP: I think it is very important to understand how complex things are, and although they come together often, analytically it is important to distinguish them, because sometimes, when you address one kind of exclusion, you create another problem. Everyone understands economic exclusion, so in some ways, governments and policies have been good at reducing some of the economic barriers that have excluded young people. Certainly, up to sixteen, nobody, I imagine, in Portugal pays for their schooling unless they want to go to a private school, so generally, economic barriers have been removed. Though of course there are still economic inequalities in the level of resources that schools have, often in the quality of teachers that are in poorer schools. So, there are still economic inequalities, but in terms of crude exclusionary aspects, to some extent you might argue that some of the superficial economic barriers have been removed, so that children can afford to go to school and education is provided free. Cultural exclusion is far more complicated, because it operates on so many levels. So, you might argue simply about teachers' expectations, that they are raced and gendered and classed; you could argue that teachers carry partial versions of the world that mean they privilege particular learners; you could argue, as many people did in the 1970s, that the curriculum is culturally loaded towards 'dead white males' so that it has less salience for a large proportion of students.

AL: Is this not what Bourdieu said?

SP: Yes, that is true, exactly: that basically schools simply reward what students already have. So, from a Bourdieusian point of view, yes. As well as a Marxist point of view, a more conventional Marxist point, you could argue that. A lot of people talk about cultural deficit within the family, but you could argue that it is a product of economic injustice, as opposed to a cultural matter. Where cultural deprivation theories sit is problematic, because they sit between economic hardship and access 
to a different culture. You see political exclusion probably at almost every level of the system, so you might argue that the people who govern and control education are the educated, so it is very much a producer-controlled thing, from Universities downwards. And the extent to which we give control, in terms of really democratising the content and nature of schooling is very limited. You could say that all these different forms of exclusion are manifest in how we organise our education systems and the experience that young people get. I do not want to talk too much about compensatory education, but you can see that different policies have tried to address - very weakly, in some ways - different aspects of this. At the moment, certainly in the United Kingdom, a lot of the political emphasis is on the political exclusion of parents and children, so that they are given more power to start their own schools, to decide on their curriculum. In Wales, all schools, by law, have to have a student council that involves the students in decision-making. A lot of the reforms are about trying to address what you might call the lack of representation, but that does nothing, really, to address the other inequalities. So, it is complex, and some people argue that, by giving parents more decision-making powers, you actually make other things worse, which is the argument against choice and markets.

JL: You mentioned something very interesting, which was about the parents setting up their own schools. Could you tell us a bit more about that?

SP: In England, they are called 'free schools', and any group of parents can put together a case for opening a new school. They will get support from the Government. It can be any kind of school which the founders believe matches how they want their children to be educated. So, for instance, there are a whole variety of faith schools under this. We have a lot of faith schools in the state-maintained sector, anyway, in the UK. Now we have many Islamic schools, we have Hindi schools, Maharaji schools, Seventh Day Adventist schools... We have schools that pride themselves on being very disciplined... So, there is a whole variety of schools.

\section{AJA: Are these like charter schools?}

SP: Similar, but charter schools vary from State to State. Free schools do not need to have qualified teachers and do not need to follow the National Curriculum.

JL: How does that work in the long term, do the children submit to national examination at some point?

SP: I would think they do, because parents would want that. It is a very right-wing policy, because it implies that parents know better than the State and the professionals.

JL: So you could have a school with no teachers, for example? 
SP: They have to have minimum health and safety requirements and they get inspected to show they are not breaking the law, but yes, you could have a school with no trained teachers.

AJA: One of the researchers participating in our project, Tiago Neves, recently published a paper ${ }^{2}$ reporting a longitudinal study, covering the past 30 years, analysing the results in schools that have been part of a national governmental programme, school-based, targeting schools in what were seen as disadvantaged contexts. The programme is diverse, so it targets different aspects of the schooling process, school dynamics, but mostly it brings additional resources to the schools: additional teachers in some situations, additional staff (psychologists, mediators, etc.). This programme has been in force for fifteen years, and what this paper shows is that this programme has had very little effect in the outcomes of these children and young people. That being said, can you explain why compensatory policies can deepen inequality?

SP: I do not want to say that compensatory reforms make things worse - although we might want to argue there are problems about cultural deficit theories - but they certainly have not been hugely successful. It is possible that things might have been even worse without them; we do not know, because it is very difficult, usually, to get very good control measures for comparison. But they certainly have not had very good results, and it is difficult to know why, but I suspect none of them have brought enough extra resources in. If you look at the ones that I know best - which we have looked at - the resources would never have been enough to address the scale of the disadvantage at almost every level in the system, from the teachers to the resources in the home, to the resources in the school. The amount of money put into them was very, very tiny, compared with overall budgets. It is also the case - and we are just talking about economic injustices - that often the targeting is very crude, so if you are talking about even quite a small area, there will be more advantaged students in it than disadvantaged students. Actually, the geography of poverty is quite fragmented, and even in a school, there are very few schools where the majority of pupils are very, very poor. In our schools, we have an indicator, free school meals - which is kind of a benefit threshold - and very few schools at secondary level have more than $30 \%$. So, the targeting is very crude: they are targeted at the particular individuals, and the level of resourcing is quite poor. As for your question, which is how do they make things worse, I think that if these interventions do not lead to measureable improvements, people think it the whole exercise is pointless. You can lose your optimism. You just think, "Why did I bother?", and that is a very dangerous thing. But I suspect it is simply because they have never really tried hard enough. The interventions have been very small compared to the level of resourcing that is needed. If I think about Education Action Zones in England, much of the money went on things that were really not

\footnotetext{
${ }^{2}$ Ferraz, H., Neves, T., \& Nata, G. (2018). A emergência e evolução da educação compensatória na teoria e na prática: Fragilidades e possibilidades. Educação, Sociedade \& Culturas, 52, 83-103.
} 
that essential. Sometimes, the resources are not used to give young people access to powerful knowledge. They might be used to set up various "therapeutic" classes or restorative justice programmes... They might be used for a whole range of things, but not about giving young people access to powerful knowledge. So, it is partly the scale of the resources and it is partly what they spend them on.

AJA: So, can we say that what Basil Bernstein proposed, many years ago, that "education cannot compensate for society", is still true?

SP: I think the point he made was in a particular point in time. This is a difficult question, because he is right, he said, "If you have a compensatory policy, you need to know what you are compensating for; that implies there is a lack of something in the home". Now, I do not have any problem with saying that a lack of resources in the home is a problem. Whether you call that a deficit theory, I do not know. I do not think that is a deficit theory; I think it is very difficult to argue that poverty is not a serious problem, and that if you live in a poor environment, in a very poor house, you may benefit from all kinds of close, connective, cultural, communal bonds, but you are not going to have access to the cultural resources that would enable you to get powerful knowledge. And I do not think that is a cultural deprivation thesis, I think that is acknowledging that poverty is bad.

AL: Our next question relates to this issue: ten years ago, you wrote a paper where you stated that compensatory education policies have failed, arguing that the main reason behind such failure is not knowing exactly what we are trying to compensate for. How are we doing today in relation to this matter? Do compensatory education policies attain better outcomes today than ten years ago? Why?

SP: I have a number of answers to this. Overall, in some ways we might be doing better with specific policies, and I can talk here about, for instance, in Wales, where we have a pupil deprivation grant, which is very focused. And, in some schools, that makes a difference, but only in some schools. System-wide, we are not doing much better. Individual schools might do better, if they are very clear in what they are using the money for. So, it has made some difference, though how sustainable it is, and how scalable it is, is unclear. What I think really frustrates me about a lot of interventions today is that the thing they are compensating for seems to be low expectations and low self-esteem. And that, I think, is a real distraction, and I can see people focus on it because it is cheap. It is much easier to talk about raising a young person's self-esteem than it is to give them access to a rich intellectual curriculum, but there is little evidence that raising self-esteem makes any difference to outcomes. There has been research that has tried to link raising expectations and aspirations to outcomes, but the link is not strong. We look at disadvantaged communities and think, "If only they had higher aspirations, they would be alright", and of course it is just not true. I think the current emphasis on raising aspirations and self-esteem is a dangerous distraction, because 
it will not make any difference. And I suspect that their aspirations are realistic; it is not that they are artificially low, they are realistic. I think that is another example of blaming the poor: "That is your fault, because you are just not aspiring high enough". That is where I think we are doing even worse; some things we are doing better, but the focus on esteem raising is a distraction.

AL: And in those few, selected cases where there have been improvements, why do you think that was?

SP: I do not know, but some schools seem to be doing something that makes a difference.

AL: Why is this not scalable, why has it not trickled down?

SP: It is partly unique, and we need detailed, very micro-level research, a bit like you are trying to do here, to look at actual processes. I am a governor of a school which has significant levels of disadvantage, where they did make a difference; they did manage to reduce the attainment gap, with their pupil deprivation grant, and some of the money they spent on school uniforms. But I would not want to suggest that as a policy, so it is difficult to know what little things make a difference. If it is buying every young person a blazer, give them something and make them feel more like a scholar or a student... But I cannot see that being a national policy that works. It could have the opposite effect, so it is difficult to look at a little thing that seems to work and then adopt it nationally.

AJA: Do you think that in these few successful cases, resilience has played a role?

SP: I do not know, because nobody knows what 'resilience' is. It is a word like 'wellbeing, that we use a lot to describe something we cannot really understand, but we do not know where it comes from or how to build it. It is just a recognition that there is something, but what it is, we do not know.

AJA: It is more of a psychologistic explanation than an sociologistic one.

SP: Yes, but it does not mean anything. When you ask them what it is, each person has a different understanding.

AL: Following the democratisation of schooling systems, there was an expectation that the school would be a decisive factor for social mobility. As you see it, has the school played such a role? Why?

SP: Yes, I think there is no doubt that schooling has played a part in increasing social mobility. The fact that we do not have a perfectly socially mobile system does 
not mean that it hasn't made a difference. There is absolutely no doubt that the democratisation of schooling has enabled people from disadvantaged backgrounds to go into middle class and better positions. Of course, some of that has to do with the change in the class structure as well, so that we have more room in the middle than we did 60 or 70 years ago. Part of it has to do with the change in labour market, so that there are more openings; part of it has to do with fairer forms of accreditation. I know that Bourdieu is right about cultural capital, we know there are biases and we know there is privileging of the already-privileged; but there is a lot of movement up and down, and between and within social classes. What education is very good at is protecting downwardly mobile middle class, but it does enable working class students to become upwardly socially mobile. I think the problem is not, "Does it help or does it not?", but "Do we want a complete meritocracy?". A meritocratic society is a very depressing place, in many ways; a meritocracy can be more unequal than the society we have now. We talk about meritocracy as the goal, but I would rather have a more equal society, even if it is a bit less meritocratic. So, I do not worry so much about social mobility, and I am less worried about meritocracy; I am more worried, simply, about the scale of inequalities. You could have a very meritocratic society, with complete social mobility, but huge levels of inequality; and it might be socially mobile in that somebody from the bottom could go all the way up to the top, but it is still hugely unequal. I think it is unlikely that would happen, because we know that privilege protects itself quite well, but I would rather worry less about social mobility and more about absolute levels of inequality. That is a preference that people have, they are just different versions of what kind of society you would like, but I think certainly, in general, schools have helped with social mobility. I think it would be very hard to argue otherwise. Certainly, they do legitimate inequalities, but they do also create opportunities.

\section{JL: And do they protect power, as you said?}

SP: Yes. The middle class parents are good at protecting the social class positions of their children, even if they do not do well in school. So, what it actually shows is that, perhaps, education is not the only factor in social mobility. If you are poor, you need education to do well; if you are middle class or affluent, education is not so important. We see this is terms of race and ethnicity as well, that black children who do well will still not get as good a job as white children who do well; there is a race penalty. So, it is a factor in mobility, but the labour market is also a problem, because it does not value qualifications equally; it values the white person with the same qualification as better than a black person. But I still would not argue that education has no role in it.

AJA: In some of the practices in our study, the representativeness of the Roma community is fairly high, so the issue of Roma students is very important. In the past few years, in Portugal, there have been some changes in educational policy and one of them has been that preschool has become compulsory for children at the age of 
4. This means that, because Roma children are starting their schooling earlier, there will more of them, later on, in primary and secondary schools. From our point of view, this poses an issue also at the level of teacher training, in that teachers are not prepared to handle these children. Although you may argue that might be the case for foreign children as well, for example, or children from religious minorities, but it is especially true for Roma children. Some of the children and young people that we engaged with, in our focus groups, were very clear in how they experienced racism from teachers. As a researcher, how would you address this, how would you explore this with these children?

SP: This is a hard question. It is difficult. Obviously - and I am sure you did - I would ask them how they would like to be treated. And I suspect they would say something like, "We want to be treated with respect". But then you would ask what it is that you want respected, and then you get to the hub of the issues about cultural differences. And if they say to you, "We want you to respect the fact that we do not always want to come to school", or "We want you to respect the fact that we want to get married at 13 ", then that immediately creates an issue, and it is one which is probably not very easily resolvable if you have a position that values particular individual rights. There are a whole lot of philosophical issues, which I am not really equipped to judge, about how you balance individual rights, the rights of the child, with familial rights, with community rights, with the rights of the State. But it seems to me that there is an incompatibility there, and I do not think, necessarily, that respect is achievable if you do not respect those rights. Clearly, there will be racism which is just unacceptable, and we are talking about the kind of crass racism; we will take it that that is completely unacceptable. But it is how you deal with a genuine conflict of cultures and values, and I think that is a discussion you would have to have with them, because, ultimately, do we respect their right to not come to school?

\section{AJA: What do we do, then?}

SP: There are similar issues that are very prevalent, particularly in England, with some of the Muslim schools; particularly, some of the free schools or the private schools for young Muslim children, where they have been taken to court. Firstly, they will separate the boys and the girls, and there is some evidence that they will give a superior education to boys, and not let the girls do the same things. But they also teach very homophobic attitudes, and some of these schools have been taken to court, for teaching homophobic and hate preaching. Now, when it breaks the law, it is easy to hold a line, but it is not very culturally sensitive. I think this is where cultural recognition does not work, because recognising difference in a superficial way is problematic. I would want to have a conversation with these Roma children.

AJA: Would it be important, in terms of teacher training, to have specific training for recognition and difference, and so on? 
SP: Yes.

AJA: We do not have that kind of appropriate training. Teacher training, in Portugal, is very focused on didactics, core curriculum. And racism against the Roma community is ingrained in Portuguese society.

SP: Yes, so there is racism and then there are fundamental cultural incompatibilities, and they are not necessarily the same thing. It is the same with issues around Islam; that there is certainly islamophobia, but it does not mean there are not also cultural incompatibilities, and the two get put together when that should not happen. 